\title{
Ruth Compton Brouwer Canada's Global Villagers: CUSO in Development, 1961-86
}

Vancouver: University of British Columbia Press, 2013. 317 pp.

\section{Tarah Brookfield}

Wilfrid Laurier University

Teaching English in South Korea, a church mission project in Kenya, travel to Guatemala, and a Development Studies MA program, were among some of the postgraduation plans of students taking my Twentieth Century Canada seminar this year. Too bad Ruth Compton Brouwer's Canada's Global Villagers: CUSO in Development, 1961-86 was not available in time to make it required reading for the class. This engaging history of the Canadian University Service Overseas (CUSO) would have helped us to compare how the millennials' international experiences diverge from those of the baby boom cohort. Although today's geopolitical landscape and employment opportunities for BA grads differ greatly, I suspect my students would have seen something of themselves in the idealism, sense of adventure, and hint of self-interest found among the early wave of CUSO volunteers. They would also have discovered how current debates over the funding, politics, and ethics of international development are not new.

Beyond contemporary relevancy, Brouwer's book is a valuable addition to recent studies in postwar internationalism and grassroots mobilization that offers a rather unique combination of political and social history. Through a critical analysis of CUSO's experience practicing and assessing the value of international development, Brouwer's book provides a new angle to better understand the young people and ideology behind Canada's evolving postwar global consciousness.

Using extensive oral history interviews with former CUSO volunteers and staff, as well as archival records, Brouwer shows the challenges of launching an ambitious development organization with sights on working in dozens of nations, in multiple fields, prior to the existence of Canadian International Development Agency (CIDA) or even before CUSO's more well-known American counterpart, the Peace Corps, 
was active. Originally the brainchild of graduate student Keith Spicer, CUSO arose from his vision of closing the development gap in recently decolonized nations by exporting Canadian expertise in education, health care, and agriculture via the labour of recent university graduates. Spicer's vision was nurtured by key university administrators across Canada who saw a value in assisting nations in need, while simultaneously building a good reputation for Canada abroad through a combination of "concrete jobs meeting real needs" and "goodwill assignments" (65). There was also the sense that the volunteers would return to Canada as global citizens, invigorated by their time abroad, and rendered able to further enhance Canada's own development. Brouwer places these incentives in the context of the Cold War battle for the hearts and minds of non-aligned African and Asian nations, where "addressing underdevelopment through economic assistance and the application of modernization theory acquired urgency and indeed came to be seen as crucial" (3) for Western nations seeking to win allies to the side of democracy and capitalism. Brouwer also demonstrates how CUSO's secular commitment to service had precedents in the missionary era, particularly in how the thousands of CUSO volunteers became "like the missionaries before them...the human face of Canada in many parts of the world" (6).

As she has done with her previous studies of female missionaries, Brouwer places great attention on the gendered nature of the CUSO volunteer experience. This is a critical point, given that women volunteers often outnumbered men, a factor partly explained by enthusiastic responses from Canadian nurses and the need for their expertise overseas. There are numerous examples throughout the text of gender influencing the volunteer experience and development activities, particularly when the cross-cultural placements held specific challenges for young, single women volunteers placed in rural villages with limited opportunities or strict social expectations for women. Yet Brouwer notes that despite frequently dealing with the sensitivity of gender issues in the field from the early-1960s, CUSO did not prioritize gender equality itself as a development tool until the mid-1970s.

Two of Canada's Global Villagers' chapters, dedicated to case studies of CUSO work in India and Nigeria, give great insight into the lessons learned model of international development. Based mainly on the reflections of staff and volunteers looking back on their experiences (many of whom are singled out as return volunteers for their multiple placements), readers are privy to a series of, sometimes heartwarming, occasionally regretful, at times dangerous, and often awkward accounts of Canadians abroad. Neither Brouwer, nor her interviewees shy away from admitting to the naiveté or floundering of CUSO personnel, often due to limited pre-travel preparation, the mismatching of some volunteers' skills to their postings, and the on-the-ground realities - be they local housing, or national politics out of synch with volunteer expectations. Most recollections include periods of culture shock, whether it was volunteers encountering racial and gender-based discrimination, or when volunteers returned home and were sickened by the over consumerism of their fellow Canadians. The section dedicated to how CUSO administrators navigated the Nigerian Civil War is an enlightening example of the organization's remarkable flexibility in balancing volunteer feedback, the shifting needs and political climate of host countries, and 
pressures to compliment Canadian foreign policy. CUSO struggled to determine what use they could be in a war zone, while still keeping their posted volunteers safe and maintaining a working relationship with the Nigerian government, whom many pro-Biafra Canadians believed was cruel and corrupt. Ultimately, Brouwer suggests that CUSO made peace with the imperfection of any of the options, pragmatically choosing to remain in the unaffected North.

Beyond enlightening readers on the history of internationalism, Canada's Global Villagers is also a welcome contribution to the history of youth. In a different book, Making the Scene: Yorkville and Hip Toronto in the 1960s, Stuart Henderson explores Canada's countercultural epicentre - four city blocks in downtown Toronto that became the destination and destiny for a cohort of Canadian youth searching for authenticity. To this often-dominant vision of youth activism in the 1960s, Canada's Global Villagers offers a compelling counterpoint, giving shape to an intertwined, yet distinct history of another popular 1960s youth activity - overseas development work. Reminiscent of their Yorkville peers, Brouwer's volunteers rejected the traditional paths that awaited them, forsaking or at least putting on hold careers and homemaking, in order to change the world and open their own minds.

Canada's Global Villagers is a highly readable exploration of Canada's non-governmental encounters with the world, and how they shaped Canadians' understanding of privilege, poverty, and globalization. A useful companion to this book would be one written by a historian of Nigeria or India, or of any of the many other countries that welcomed CUSO in its early years. Such a pairing would help us to truly understand the short- and long-term impact of CUSO's good intentions and planning on communities and individuals overseas. 